Boise State University

ScholarWorks

Psychological Sciences Faculty Publications and

Presentations

Department of Psychological Science

$2-1-2012$

\title{
Body Dissatisfaction: Commitment, Support and Trust in Romantic Relationships
}

Lilia Juarez

Boise State University

Mary Pritchard

Boise State University 


\title{
Body Dissatisfaction: Commitment, Support and Trust in Romantic Relationships
}

\author{
Lilia Juarez and Mary Pritchard \\ Boise State University
}

\begin{abstract}
Research investigating dimensions of relationship quality (Markey, Markey, \& Birch, 2001; Pierce, Sarason, \& Sarason, 1996) has suggested that aspects of relationship quality (e.g., commitment, support, trust) are related to lower levels of body dissatisfaction in women. However no studies have examined the effect of all three measures of relationship quality on body dissatisfaction simultaneously. Trust and support correlated with body dissatisfaction in men and women. Additionally the results showed that lack of support is a predictor of body dissatisfaction in men, lack of trust is a predictor in women; relationship commitment did not appear to relate to body dissatisfaction.
\end{abstract}

Keyword: body dissatisfaction, romantic relationships, trust, support, and commitment

Body image dissatisfaction is considered to be the "negative subjective evaluation of one's physical body" (Stice \& Shaw, 2002, p. 985). Body image dissatisfaction is related to having a higher body mass index (BMI), greater likelihood of binge eating, and higher depression in female university students (Saules, Collings, Wiedemann, \& Fowler, 2009). In addition, Mora-Giral et al. (2004) suggest that college females with a high level of body image dissatisfaction are at risk of developing disordered eating behaviors (subclinical) and eating disorders (clinically diagnosed) (see also Saules et al., 2009). This is alarming given the high number of women who feel dissatisfied with their bodies (Stice \& Shaw, 2002). Moreover, in today's society body image dissatisfaction does not discriminate; it seems that men are catching up to women and are becoming just as susceptible to the sources that promote thin or muscular body ideals (O'Dea \& Abraham, 2002). In fact, body dissatisfaction and dieting are now considered normative in both male and female adolescents (Cook-Cottone \& Phelps, 2006; Polivy \& Herman, 1987) and adults (French, Jeffrey, \& Murray, 1999; Neumark-Sztainer, Sherwood, French, \& Jeffrey, 1999; Polivy \& Herman, 1987). Given the aforementioned research suggesting that body image dissatisfaction may jumpstart various unhealthy behaviors, lifestyles and disorders (i.e., depression, obesity, and disordered eating behaviors), it is important to examine the factors that contribute to body image dissatisfaction.

Although media consumption has been blamed for young adults' warped perceptions of ideal body types for men and women (Kjelsås, Bjørnstrøm, \& Götestam, 2004), media is not the only influence on those perceptions. According to Cossrow, Jeffery, and McGuire (2001), women's body dissatisfaction is also impacted by everyday interactions with people. Additionally, Nichter (2000) suggested that negative interactions with romantic partners might be associated with body dissatisfaction. According to Swann, Rentfrow, and Guinn (2003), this may be due to the feedback romantic partners receive from one another that can impact self-evaluations, positive or negative. Murray, Touyz, and Beumont (1995) found that most women and one-third of men report that members of the opposite sex impact their eating, exercise habits, and body image. In addition, Sheets and Ajmere (2005) reported that some college students criticize their romantic partners' weight.

Although most research focuses on the detrimental effects of significant other's comments on their partner's body dissatisfaction, some research suggests that such involvement may also be positive. Sheets and Ajmere (2005) proposed that romantic partners could be buffers against pressures to be thin and muscular. Morrison et al. (2009) also suggest that romantic relationships could serve as a "protective factor" that would perhaps prevent or abate concerns about weight, eating, and shape (see also Whisman, Sheldon, \& Goering, 2000). Therefore, young adults in romantic relationships could potentially be less likely to be dissatisfied with their bodies.

Given the aforementioned impact that partners have on perceptions of self it is proposed in this study that relationship quality or specific factors in relationship quality such as commitment, support, and trust could ameliorate or prevent body dissatisfaction in young adults. For example, $61 \%$ of female college students reported that romantic relationships had improved their body image (Ambwani \& Strauss, 2007). On the other hand, if 
relationship quality is low, it could have a negative impact on body satisfaction. For example, Markey et al. (2001) found that when poor relationship quality in marriage was present, there were more unhealthy behaviors in the female partners. Below, we will discuss these relationship quality factors.

\section{Relationship commitment}

Commitment to one's romantic relationship is an important predictor of relationship adjustment and stability, as well as perceived and actual likelihood of relationship termination and of marriage (Rhoades, Stanley, \& Markman, 2010). In addition, relationship commitment is positively correlated to intimacy (Ha, Overbeek, de Greef, Scholte, \& Engels, 2010), relationship satisfaction (Goodboy \& Myers, 2010; Lewandowski, Nardone, \& Raines, 2010), partner liking, and partner respect (Goodboy \& Myers, 2010). Thus, it is perhaps not surprising that relationship commitment is related to body satisfaction, especially in females as women worry more than men that their partners' attraction to them will wane if they gain weight (Campbell, 2001). Thus, the relationship between commitment and body satisfaction may exist because romantic partners may interpret or perceive low commitment as a form of rejection (Rill, Baiocchi, Hopper, Denker, \& Olson, 2009). If they believe this rejection is based on their body size and shape, it could lead to even lower body satisfaction and disordered eating behaviors to compensate for the rejection (Duemm, Adams, \& Keating, 2003). On the other hand, it is possible that those in a committed relationship will worry less about their body size and shape because they know their partners accept them for who they are (Williams \& Hickle, 2010). Unfortunately, few studies have examined this question directly.

\section{Relationship support}

Research suggests that partner support predicts greater relationship quality (Overall, Fletcher, \& Simpson, 2010), and tends to grow the longer one has been in a relationship (Connolly \& Johnson, 1996). Research by Berndt and Hestenes (1996) implies that support can be used as a moderator in the reduction of eating or body image dissatisfaction. Support in romantic relationships may work to the advantage of the prevention of body image dissatisfaction. While pressure from other sources (i.e., media) may be present, if a romantic partner feels that he or she is supported regardless of their physical appearance, then perhaps it will lessen the impacts of pressures that would or could lead to body image dissatisfaction. According to Juda, Campbell, and Crawford (2004), low support from family and romantic partners is an important factor for dieting symptomology in women. Research studies also show that the best way to successfully decrease a negative body image in women is through support of a romantic partner (Pierce et al., 1996; Weller \& Dziegielewski, 2004). However, little is known about the effect of relationship support on men's body satisfaction.

\section{Relationship Trust}

According to Wieselquist (2009), trust predicts relationship satisfaction, and in fact, may be the most important 'ingredient' in a relationship (Campbell, Simpson, Boldry, \& Rubin, 2010; Simpson, 2007). When a relationship is filled with trust, there may less self-doubt or dissatisfaction with the self and specifically, with body image. Robertson (2009) found correlations between higher levels of self-esteem and greater relationship satisfaction, intimacy and trust in romantic relationships. Weller and Dziegielewski (2004) also found that women with lower levels of relationship satisfaction and trust had greater anxiety over their appearance. Thus, relationship trust may be a key component in predicting body satisfaction in women, but little is known about these relationships in men.

\section{Present Study}

Recent research shows that women and men are equally at risk of body dissatisfaction due to the many sources of pressure to conform to the ideal body shapes. Although romantic relationships have been implicated in having negative effects on body satisfaction, positive effects have also been found (Morrison et al., 2009; Sheets \& Ajmere, 2005). Studies (Berndt \& Hestenes, 1996; Markey et al., 2001; Pierce et al., 1996) have shown that women in romantic relationships that report higher levels of commitment, support, and trust also tend to report lower levels of body dissatisfaction. Nonetheless there is a dearth of direct evidence that corroborates that commitment, support, and trust are associated with lower body dissatisfaction, and no studies have examined all three variables at the same time in both men and women. The aim of this study is to investigate the relationships between commitment, support, and trust in romantic relationships and body dissatisfaction in male and female college students. 
It is important to understand how commitment, support, and trust in romantic relationships influence body image dissatisfaction. This will allow social and health psychologists to know more about factors that can be used as buffers in order to reduce such dissatisfaction or to prevent it. This research will also have a clinical use, especially in the etiology of disordered eating behaviors and muscular dysmorphia, as well as self-esteem in college students. Finally, this research will be most useful in the college population, specifically those that are in romantic relationships.

We propose three hypotheses: Hypothesis 1: commitment level will correlate with a lower level of body image dissatisfaction. Hypothesis 2: increased support will correlate with a lower level of body image dissatisfaction. Hypothesis 3: increased trust will correlate with a lower level of body image dissatisfaction. Overall we predict that increased relationship quality (commitment, support, and trust) will be strong predictors of lower body dissatisfaction in both men and women.

\section{Method}

\section{Participants}

Participants consisted of 426 General Psychology 101 students from a northwest university, who were in a romantic relationship at the time of the study. General Psychology students were recruited through Experimetrix and SONA systems to complete an online survey through Qualtrics, a survey software program. Students were awarded credit upon completion of the survey. Out of the 426 students who participated in this study, $60 \%$ were females and $40 \%$ were males. Students participating in the study were 18 years old or older. The average age was $21.88(\mathrm{SD}=5.71)$ with ages ranging from 18-58 years old. The majority of the students were Caucasian $(81.5 \%$ ), with $8.5 \%$ Hispanic/Latino, 3.8\% Asian, 2.8\% African American, 1.2\% Native Americans and 1.4\% Pacific Islander.

\section{Materials}

Body image dissatisfaction. Body image dissatisfaction was measured with the Body Dissatisfaction subscale of the revised Eating Disorder Inventory (EDI-3; Garner, 1991) which was designed to asses overall body image dissatisfaction. The subscale contains nine statements (i.e., I think my hips are too big, I think my thighs are too big, and I feel satisfied with the shape of my body) that were rated on a 6-point Likert Scale ( $1=$ always to $6=$ never). The items were summed to create a scale score $(\alpha=.91)$.

Commitment. Commitment was measured with the commitment subscale of the Triangular Theory of Love Scales (Tzeng, 1993). The scale measures commitment with statements such as "I view my commitment to my romantic partner as a solid one, I plan to continue my relationship with my romantic partner, and I cannot imagine ending my relationship with my romantic partner." Items were rated on a 9-point Likert scale ( $1=$ not at all to $9=$ extremely). The commitment subscale is scored by obtaining the average rating of the items, with higher scores indicating a greater commitment $(\alpha=.97)$.

Significant other support. Significant other support was assessed with the Significant Others Scale (SOS; Power, Champion, \& Aris, 1988). The scale measures perceptions of emotional support and practical support from a list of significant others; for this study only the "spouse/partner" was used as a significant other. Participants were asked to respond to questions (i.e., to what extent can you: [trust, lean on, get physical comfort] from your romantic partner or spouse, resolve unpleasant disagreements if they occur). Each question was rated on a 7-point Likert scale $(1=$ always to $7=$ never). The item responses are averaged to create a scale score, the higher the score indicates higher support $(\alpha=.90)$.

Trust. Trust was measured with the Trust Scale (Rempel, Holmes \& Zanna, 1985). The scale consists three subscales, a total of 17 statements regarding trust in the current relationship (i.e., I can rely on my partner to react in a positive way when I expose my weaknesses to him/her, When I share my problems with my partner, I know he/she will respond in a loving way even before I say anything). Each item was rated on a 7-point Likert scale (1=strongly disagree to $7=$ strongly agree). Item ratings were summed to create a scale score, higher scores indicate a higher trust level $(\alpha=.91)$. 


\section{Procedure}

Students were asked to register for the survey in order to have access to the survey. Students then accessed the survey website (Qualtrics) and answered the survey questions without any time constraints. A valid student identification number was provided at the end of the survey along with an email in order to receive credit. Data was then analyzed through SPSS software.

\section{Results}

Looking at the relationships between body image dissatisfaction and relationship quality (commitment, trust, and support) for women, the results showed a negative correlation between body image dissatisfaction and support. A negative correlation was also found between body image dissatisfaction and trust (see Table 1). There was no significant relationship between body image dissatisfaction and commitment (see Table 1). Similarly, for men, body image dissatisfaction was negatively correlated with support and trust, but there were no significant correlations between commitment and body image dissatisfaction (see Table 2).

\section{Predictors of Body Image Dissatisfaction in Men and Women}

To find the predictors of body image dissatisfaction for men and women, a separate regression analysis was done for each gender. Because we wanted to know not only what variables predicted body dissatisfaction, but also the order of their importance, the stepwise regression method was chosen. For men the only predictor of body image dissatisfaction was support, $\mathrm{R}^{2}=.04, \mathrm{~F}(1,157)=6.62, \mathrm{p}<.05$. On the other hand, the sole predictor of body image dissatisfaction for women was trust, $\mathrm{R}^{2}=.04, \mathrm{~F}(1,251)=10.15, \mathrm{p}<.01$ (see Table 3). No other variables were entered into the equation.

\section{Discussion}

The present study proposed three hypotheses: 1) higher commitment levels would correlate with lower levels of body image dissatisfaction, 2) increased support would correlate with a lower level of body image dissatisfaction, and 3) increased trust would correlate with a lower level of body image dissatisfaction. In addition we predicted that increased relationship quality (commitment, support, and trust) would be strong predictors of lower body dissatisfaction.

\section{Relations of Commitment to Body Image Dissatisfaction}

Our results showed that relationship commitment was not correlated with body image dissatisfaction in either men or women. We hypothesized that commitment would be in some way related, as Rill et al. (2009) showed that low commitment may induce a sense of rejection in women and, thus, may lead to body image dissatisfaction (Duemm et al., 2003). However, our results did not find this to be the case. It is possible that the lack of significance of commitment as contributing factor may be due to the variability in the length of relationships across all participants. However, the present study did not closely analyzed length of relationship. Future research should examine this possibility further.

\section{Trust and Body Image Dissatisfaction}

A negative correlation between trust and body image dissatisfaction was found in both men and women; though the relationship was weak, it was still significant. Studies have shown that high levels of overall self-esteem are related to trust (Robertson, 2009), and women with low levels of trust in relationships have more anxiety over their body image (Weller \& Dziegielewski, 2004). Our regression analyses did in fact show that low levels of trust predicted body dissatisfaction in women, but not in men. Thus, relationship trust seems to be more important for women than men, at least in the realm of body dissatisfaction, and could possibly indicate that men are not threatened or comforted by the presence of trust. Thus, it does not seem to have an impact on their body image dissatisfaction. Another possible explanation could be that relationship length of our participants might have varied. While some could have been in a relationship for more than a year, others were most likely still in the beginning stages of their relationship. This could mean that trust is not a quality that was thoroughly developed in the relationship and thus it could have affected the results of our correlations. Future research should explore this idea in both men and women. 


\section{Support and Body Image Dissatisfaction}

Support and body image dissatisfaction were negatively correlated in women and in men. Both correlations were relatively weak but significant. The relationship between support and body image dissatisfaction found in our study supports previous research by Berndt and Hestenes (1996), showing that support could be a moderator for body image dissatisfaction (see also Juda et al., 2004; Pierce et al., 1996). Thus, if an individual is receiving support when they are feeling bad about their body image, then those feelings will be countered by the support, thereby making the support a buffer to the body image dissatisfaction (Morrison et al., 2009). Perhaps the reason for the significance may be due to the kind of support being offered and received. If the support is directly aimed towards body image then the results from previous research would be further supported. However, if the support is in the manner of kind gestures or support for their achievements, it may not affect body dissatisfaction. Research studies should inquire further into the different support types in regards to buffering body image dissatisfaction.

Interestingly, a lack of support was the sole predictor of body dissatisfaction in men, but did not predict body dissatisfaction in women.Given the correlational results, we expected that support would be a predictor of body image dissatisfaction in both men and women. Thus, it is interesting that trust was the sole predictor of body image dissatisfaction in women, when the strength of the relationship between trust and support and body image dissatisfaction were the same in both men and women. It seems that women put more weight in trust than in support, at least where body image issues are concerned. Thus it could mean that women feel more satisfied with their bodies when they know or feel they are in a trusting relationship (Robertson, 2009; Weller \& Dziegielewski, 2004). This could be due to the idea that if a partner is no longer attractive, they will seek out another partner that is more attractive. In men, body image dissatisfaction may not be affecting men in the same way or depth that it does in women; thus a little support could counter men's body image dissatisfaction. In other words men may need little to battle body image dissatisfaction, whereas women may need much more. Future research should examine this possibility.

\section{Limitations}

The study was conducted through an online survey and cannot ensure complete honesty from the participants. In addition, the study was a correlational study; thus causality and relationship direction cannot be ascertained. Relationship length was not assessed in this present study, therefore little can be known about the implications to the results of our study, specifically in regards to commitment. In addition, trust, commitment, and support are complex measures. It could be that had we used more comprehensive measures of relationship quality, we would have obtained different results. Finally, the amount of variance accounted for was minimal. Clearly other factors influence body dissatisfaction; future studies should examine this question further and determine how much, if any, of a contribution relationship quality factors make to overall body dissatisfaction when other factors (e.g., media influence, family influence, peer influence) are accounted for.

\section{Conclusion}

Although we see significant relationships between trust and support and body dissatisfaction in women and men, ultimately lack of relationship trust is the sole predictor of body image dissatisfaction in women. In men, lack of relationship support is the only factor predictive of body image dissatisfaction. The relationships in both men and women show that support and trust act as buffers of body image dissatisfaction and may tie into Sheets and Ajmere's (2005) proposed idea of romantic partners as buffers against body image pressures. Overall the study shows that though lack of commitment is not a contributing factor to body image dissatisfaction, lack of support and trust are. The current study's research could be used to guide new areas of inquiry, such as how different types of support could directly and indirectly affect body image dissatisfaction. Commitment and relationship length should be examined closer. Finally, the present study did not examine how important each of the variables (i.e., commitment, trust, and support) was to each gender. If there are gender differences in the importance of different relationship qualities, one would expect gender differences in the ways and amounts that each quality may contribute to body image satisfaction. 


\section{References}

Ambwani, S., \& Strauss, J. (2007). Love thyself before loving others? A qualitative and quantitative analysis of gender differences in body image and romantic love. Sex Roles, 56(1-2), 13-21. doi:10.1007/s11199-006-91437

Berndt, T. J., \& Hestenes, S. L. (1996). The developmental course of social support: Family and peers. In L. Smolak, M. P. Levine, \& R. Striegel-Moore (Eds.), The developmental psychopathology of eating disorders: Implications for research, prevention, and treatment (pp. 77-106). Erlbaum: Mahwah, NJ.

Campbell, W. W. (2001). Thinness in women: The impact of female body weight on relationship satisfaction and commitment. Unpublished doctoral dissertation, Indiana State University, Terre Haute, IN.

Campbell, L., Simpson, J. A., Boldry, J. G., \& Rubin, H. (2010). Trust, variability in relationship evaluations, and relationship processes. Journal of Personality and Social Psychology, 99(1), 14-31. doi:10.1037/a0019714

Connolly, J. A., \& Johnson, A. M. (1996). Adolescents' romantic relationships and the structure and quality of their close interpersonal ties. Personal Relationships, 3(2), 185-195. doi:10.1111/j.1475-6811.1996.tb00111.x

Cook-Cottone, C. P., \& Phelps, L. (2006). Adolescent eating disorders. In G. Bear, K. Minke, \& A. Thomas (Eds.), Children's needs III: Understanding and addressing the developmental needs of children (pp. 977-988). Bethesda, MD: National Association of School Psychologists Publications.Retrieved from EBSCOhost.

Cossrow, N., Jeffery, R. W., \& McGuire, M. T. (2001). Understanding weight stigmatization: A focus group study. Journal of Nutrition Education, 33(4), 208-215.

Duemm, I., Adams, G. R., \& Keating, L. (2003). The addition of sociotropy to the dual pathway model of bulimia. Canadian Journal of Behavioural Science/Revue canadienne des sciences du comportement, 35(4), $281-291$. doi:10.1037/h0087208

French, S. A., Jeffrey, R. W., \& Murray, D. (1999). Is dieting good for you?: Prevalence, duration and associated weight and behaviour changes for specific weight loss strategies over four year in US adults. International Journal of Obesity and Related Metabolic Disorders: Journal of the International Association for the Study of Obesity, 23, 320-327.

Garner, D. M. (1991). Eating Disorder Inventory-2 professional manual. Odessa, Florida: Psychological Assessment Resources, Inc.

Goodboy, A. K., \& Myers, S. A. (2010). Relational quality indicators and love styles as predictors of negative relational maintenance behaviors in romantic relationships.Communication Reports, 23(2), 65-78. doi:10.1080/08934215.2010.511397.

Ha, T., Overbeek, G., de Greef, M., Scholte, R. J., \& Engels, R. E. (2010). The importance of relationships with parents and best friends for adolescents' romantic relationship quality: Differences between indigenous and ethnic Dutch adolescents. International Journal of Behavioral Development, 34(2), 121-127.

Juda, M., Campbell, L., \& Crawford, C. (2004). Dieting symptomatology in women and perceptions of social support: An evolutionary approach. Evolution and Human Behavior, 25(3), 200-208.

Kjelsås, E., Bjørnstrøm, C., \& Götestam, K. (2004). Prevalence of eating disorders in female and male adolescents (14-15 years). Eating Behaviors, 5(1), 13-25.

Lewandowski, G. R., Nardone, N., \& Raines, A. J. (2010). The role of self-concept clarity in relationship quality. Self and Identity, 9(4), 416-433. doi:10.1080/15298860903332191 
Markey, C. N., Markey, P. M., \& Birch, L. L. (2001). Interpersonal predictors of dieting practices among married couples. Journal of Family Psychology, 15(3), 464-475.

Mora-Giral, M., Raich-Escursell, R.M., Segues, C.V., Torras-Claraso, J., \& Huon G. (2004). Bulimia symptoms and risk factors in university students. Eating and Weight Disorders, 9(3),163-169.

Morrison, K., Doss, B. D., \& Perez, M. (2009). Body image and disordered eating in romantic relationships. Journal of Social \& Clinical Psychology, 28(3), 281-306. Retrieved from EBSCOhost.

Murray, S. H., Touyz, S. W., \& Beumont, P. J. (1995). The influence of personal relationships on women's eating behavior and body satisfaction. Eating Disorders, 3(3), 243-252.

Neumark-Sztainer, D., Sherwood, N. E., French, S. A., \& Jeffrey, R. W. (1999). Weight control behaviors among adult men and women: Cause for concern? Obesity Research, 7(2), 179-188.

Nichter, M. (2000). Fat talk: What girls and their parents say about dieting. Cambridge, MA Harvard University Press.

O'Dea, J., \& Abraham, S. (2002). Eating and Exercise disorders in young college men. Journal of American College Health, 50(6), 273-278.

Overall, N. C., Fletcher, G. O., \& Simpson, J. A. (2010). Helping each other grow: Romantic partner support, selfimprovement, and relationship quality. Personality and Social Psychology Bulletin, 36(11), 1496-1513. doi: $10.1177 / 0146167210383045$

Pierce, G. R., Sarason, I. G., \& Sarason, B. R. (1996). Coping and social support. In M.Zeider, \& N. Endler (Eds.), Handbook of coping: Theory, research, \& applications pp. 434-451). New York: John Wiley \& Sons, Inc.

Polivy, J., \& Herman, C. P. (1987). Diagnosis and treatment of normal eating. Journal of Consulting and Clinical Psychology, 55(5), 635-644.

Power, M., Champion, L., \& Aris, S. (1988). The development of a measure of social support: The Significant Others (SOS) Scale. British Journal of Clinical Psychology, 27(4) , 349-358.

Rempel, J. K., Holmes, J. G., \& Zanna, M. P. (1985). Trust in close relationships. Joumal of Personality and Social Psychology, 49(1), 95-112.

Rhoades, G. K., Stanley, S. M., \& Markman, H. J. (2010). Should I stay or should I go? Predicting dating relationship stability from four aspects of commitment. Journal of Family Psychology, 24(5), 543-550. doi: $10.1037 / \mathrm{a} 0021008$

Rill, L., Baiocchi, E., Hopper, M., Denker, K., \& Olson, L. (2009). Exploration of the relationship between selfesteem, commitment, and verbal aggressiveness in romantic dating relationships. Communication Reports, $22(2), 102-113$.

Robertson, R. K. (2009). Body image, self-esteem, and interpersonal relationships in adulthood. (Master's thesis, Auckland University of Technology). Retrieved from http://www.google.com/search?q=body.

Saules, K. K., Collings, A. S., Wiedemann, A. A., \& Fowler, S. L. (2009). The relationship of body image to body mass index and binge eating: The role of cross-situational body image dissatisfaction versus situational reactivity. Psychological Reports, 104(3), 909-921.

Sheets, V., \& Ajmere, K. (2005). Are romantic partners a source of college students' weight concern? Eating Behaviors, 6(1),1-9. 
Simpson, J. A. (2007). Foundations of interpersonal trust. In A. W.Kruglanski \& E. T.Higgins (Eds.), Social psychology: Handbook of basic principles (2nd ed., pp. 587-607). New York, NY: Guilford Press.

Stice, E., \& Shaw, H. E. (2002). Role of body dissatisfaction in the onset and maintenance of eating pathology: A synthesis of research findings. Journal of Psychosomatic Research, 53(5), 985-993. doi:10.1016/S00223999(02)00488-9

Swann, W. B., Rentfrow, P. J., \& Guinn, J. S. (2003). Self-verification: The search for coherence. In M. R. Leary, \& J. P.Tangney (Eds.), Handbook of self and identity (pp. 367-383). New York Guilford Press.

Tzeng, O.C. S. (1993). Measurement of love and intimate relations. Westport, CT.: Greenwood Publishing Group, Inc.

Weller, J., \& Dziegielewski, S. (2004). The relationship between romantic partner support styles and body image disturbance. Journal of Human Behavior in the Social Environment, 10(2), 71-92.

Whisman, M., Sheldon, C., \& Goering, P. (2000). Psychiatric disorders and dissatisfaction with social relationships: Does type of relationship matter? Journal of Abnormal Psychology, 109(4), 803-808.

Wieselquist, J. (2009). Interpersonal forgiveness, trust, and the investment model of commitment. Journal of Social and Personal Relationships, 26(4), 531-548.

Williams, L., \& Hickle, K. E. (2010). "I know what love means": Qualitative descriptions from Mexican American and White adolescents. Journal of Human Behavior in the Social Environment, 20(5), 581-600.

doi:10.1080/10911351003673278 
Table 1

Correlations between Body Image Dissatisfaction and Relationship Quality in Women

\begin{tabular}{|c|c|c|c|c|c|}
\hline Measure & Mean(SD) & 1 & 2 & 3 & 4 \\
\hline 1. Commitment & $5.90(1.2)$ & -- & $.59 * * *$ & $.62 * * *$ & -0.07 \\
\hline 2. Trust & $87.3(13)$ & & -- & $.80 * * *$ & $-0.20 * *$ \\
\hline 3. Support & $5.84(1.0)$ & & & -- & $-0.17 * *$ \\
\hline $\begin{array}{l}\text { 4. Body } \\
\text { Dissatisfaction }\end{array}$ & $8.00(8.0)$ & & & & -- \\
\hline
\end{tabular}

Note. $* * \mathrm{p}<.01, * * * \mathrm{p}<.001$ 
Table 2

Correlations between Body Image Dissatisfaction and Relationship Quality in Men

\begin{tabular}{|c|c|c|c|c|c|}
\hline Measure & Mean(SD) & 1 & 2 & 3 & 4 \\
\hline 1. Commitment & $5.90(1.2)$ & -- & $.69 * * *$ & $.79 * * *$ & -0.08 \\
\hline 2. Trust & $87.3(13)$ & & -- & $.76^{* * *}$ & $-0.18 *$ \\
\hline 3. Support & $5.84(1.0)$ & & & -- & $-0.20 *$ \\
\hline $\begin{array}{l}\text { 4. Body } \\
\text { Dissatisfaction }\end{array}$ & $8.00(8.0)$ & & & & -- \\
\hline
\end{tabular}

Note: $* \mathrm{p}<.05, * * * \mathrm{p}<.001$ 


\section{Table 3}

\section{Predictors of Body Image Dissatisfaction in Women and Men}

\begin{tabular}{lllllll} 
Variable & \multicolumn{3}{c}{ Women } & & \multicolumn{3}{c}{ Men } \\
\cline { 2 - 3 } \cline { 5 - 6 } & B & SE B & $\beta$ & & SE B & $\beta$
\end{tabular}

Step 1

Trust

$\begin{array}{llllll}-0.11 & 0.03 & -.20^{* *} & -- & -- & --\end{array}$

Support

$\begin{array}{llllll}-- & -- & -- & -1.60 & 0.62 & -0.20^{*}\end{array}$

Note: $* \mathrm{p}<.05,{ }^{* *} \mathrm{p}<0.01$ 